\title{
Engaging students in creative music making with musical instrument application in an online flipped classroom
}

\author{
Davy T. K. NG ${ }^{1}$ D $~$ Ellen H. L. NG ${ }^{2}$ Samuel K. W. $\mathrm{CHU}^{1}$ (D)
}

Received: 31 January 2021 / Accepted: 25 April 2021 / Published online: 2 July 2021

(c) The Author(s), under exclusive licence to Springer Science+Business Media, LLC, part of Springer Nature 2021

\begin{abstract}
In K-12 schools, classes are forced to transform online due to the class suspension amid the COVID-19 pandemic. Educators began to design alternative ways to conduct some meaningful learning activities for their students. However, not all subject disciplines could be easily transformed online, especially for those requiring much social interaction and creation processes. In this article, we explore the learning processes through learning Shubailan, a form of music folk-talk-singing, with a mobile instrument application called muyu in an online flipped classroom among $122 \mathrm{sec}-$ ondary school students in Hong Kong. The opportunities can encourage students to learn music theories and instruments about Shubailan, and create a Shubailan piece through 6-lesson music learning. To gain more online face-to-face time for collaboration, flipping the online classroom is adopted in this study to engage students in lesson preparations via preassigned recorded videos and collaborative activities during face-to-face online lessons. In this study, a mixed research method was employed with the use of a learning satisfaction survey, teachers' observations and semi-structured interviews. We found that this strategy could effectively motivate students to learn music and improve their music knowledge in Shubailan. This article presents evidence of implementing the online flipped classroom approach to enhance students' satisfaction and knowledge acquisition throughout Shubailan music making processes, and offers recommendations for online music educators. Results provide a set of innovative pedagogical approaches to teach music in an online alternative mode during the difficult times.
\end{abstract}

Keywords Online flipped classroom · Flipped classroom · Music mobile service · Music learning $\cdot$ Musical instrument application $\cdot$ COVID-19

Davy T. K. NG

davyngtk@ connect.hku.hk

Extended author information available on the last page of the article 


\section{Introduction}

The COVID-19 pandemic and the resulting imposition of social distancing had consequences in various subject disciplines ( $\mathrm{Ng} \&$ Chu, 2021a; $\mathrm{Ng}$ et al., 2020; $\mathrm{Ng}$ et al., 2020), especially seriously affecting the instructional design of music lessons and the relationship between music teachers and students. One reason is that music learning involves much social belonging, collaboration and affiliation (Philippe et al., 2020). Recent studies on collaborative creative music making activities (Nielsen et al., 2018; Sangiorgio, 2015), improvised interaction to make music friends (Aucouturier \& Canonne, 2017), and high-level performers in classical orchestras (Biasutti, 2013) has highlighted the social nature of collaboration, communication and companionship in music education. Such collaborative activities could encourage music learners to share co-constructed artistic ideas and knowledge in their learning groups, and to play out at individual and societal levels of training and performance such as rehearsals, recitals, solo performances, contests and concerts (Philippe et al., 2020). However, during the pandemic, these collaborative music learning activities became impossible and educators need to design an online alternative mode of instruction.

\subsection{Using technology in music education}

Prior literature suggested that using digital technologies in blended or online learning such as wiki, simulation, social networking sites and social media tools could effectively support collaborative learning in various disciplines and grade levels (e.g., Chu et al., 2019; Ng, 2021; Ng \& Chu, 2021b). However, studies criticised that research on understanding the effectiveness of online pedagogy for music learning is underdeveloped (e.g., Edward et al., 2018; Pike, 2017). In fact, there are multiple advantages of teaching music in online and computer-aided environments. For example, online music learning enhances students' flexible learning (Biasutti, 2015), allows creative opportunities for music making in studio production (King \& Himonides, 2016), encourages students to exchange dialogues for collaboration and promotes effective music knowledge acquisition (Adileh, 2012). However, there could be many teaching challenges when transforming to an online alternative mode. First, the notable latency in web-conferencing environments due to internet bandwidth will limit the smoothness of face-to-face online learning (Johnson, 2017). Second, it may deteriorate the interactions between music teachers and students when expressing and performing music in social events such as music practices and orchestra (Philippe et al., 2020). Third, motivating students in online music learning environments could be challenging and educators need to pay extra effort to redesign their pedagogical approaches (Bowman, 2014).

After reviewing the advantages and challenges of online music learning, the next is to know how educators adopt online instructional strategies to teach music based on evidence-based studies. Ho (2007) described that multimedia technologies such 
as interactive presentations, video and recordings could help students learn music through listening to music, reading score, hearing musical instruments, and reading biographical, cultural and historical background among 1741 students in 15 Shanghai secondary schools. Kruse and Veblen (2012) examined 40 YouTube folk/traditional music instructional videos and found that most videos taught music instrumental technique (73\%), music theory (58\%) and melody instruction (58\%). The online instructors modelled the correct and incorrect ways of playing the music instrument and provided pedagogical advice for students to address potential problems (Kruse \& Veblen, 2012). Moreover, these recorded videos demonstrated the use of physiological prompts (e.g., hand shape and placement), and simple music instruments or equipment (e.g., music picks, tuning pegs, wooden sticks) to scaffold students in music understandings. These findings shed lights on how teachers adopt recorded videos and social media (YouTube) to design their online music instruction. In addition, Johnson (2017) claimed that social-constructivist activities with collaborative learning tasks and community interaction, as well as digital illustrations such as procedural demonstrations are necessary to enable students to imitate teachers to play and learn music in groups. During the COVID-19 pandemic, Serdaroglu (2020) used YouTube as the channels for the London Symphonic Orchestra to share their expertise and educational content to create safe and trustworthy resources designed particularly for children, thus supporting the online music education.

Emerging technologies have already created learning opportunities that challenge the traditional pedagogical approaches in music learning through mobile services and web-conferencing software (Cho et al., 2019; Sabet, 2020). Prior studies demonstrated that recent musical instrument applications (apps) such as Echobo and Garageband could successfully engage secondary school students to participate in performing blended learning practices with their mobile devices (e.g., Lee \& Freeman, 2013; Väkevä, 2010; Wise, 2016). Bauer (2014) explained that various musical instrument apps used in current society by young people, such as iTunes and Spotify, be regarded as a manifestation of collaborative possibilities. Hu (2019) further found that music mobile services such as QQ Music could enhance music information retrieval and provide users shareable digital libraries which have great potential for informal music learning. Pike and Shoemaker (2017) employed digital pianos, internet MIDI software, acoustic pianos and Skype video-conferencing software to teach primary students sight-reading in a distance learning mode. They found that both groups (online or face-to-face classroom learning) could enhance their sight-reading ability and learning attitude in terms of enthusiasm, motivation and confidence. During the pandemic, Johnson and Merrick (2020) adopted the innovative uses of Zoom, a web-conferencing software, to support students' wellbeing, communication and connection in a socially constructed environment among teachers and students. With digital affordances, digital technologies could effectively meet the teaching challenges of distance learning through connecting with their teachers and classmates via online platforms, enhancing students' learning motivation, autonomy and interest in music (de Bruin, 2021; Pike \& Shoemaker, 2013). 


\subsection{Flipping the music classroom}

The flipped classroom approach has been regarded as a successful form of blended learning in many subject disciplines (Zainuddin et al., 2019). With the support of learning technologies, students could study preassigned digital materials such as recorded videos, readings and simple tasks so that the teachers will be able to conduct activities that build students higher-order thinking skills in the face-to-face lessons (Dong et al., 2019; Jong et al., 2019). Most frequently, it is done by requiring students to view teacher- or publisher-created videos outside of their class. During the face-to-face lessons, students will be able to have more interaction with students, instead of lecturing. This way, flipping the classroom inverts the conventional pedagogies to engage students in direct music instruction through digital materials via an online platform and interactive activities during face-to-face classroom learning (Zainuddin et al., 2019).

During the outbreak, the flipped classroom becomes an online mode such that students need to study the preassigned materials first before their face-to-face online sessions (Stöhr et al., 2020; Tang et al., 2020). The preassigned materials could be recorded lectures, recordings, readings and simple tasks. During the face-to-face online sessions, teachers guide students in higher order thinking interactive activities such as music performance, making and problem-solving. This makes the learning environment become a dynamic and interactive place for students to apply concepts with their creativity. Second, as students pay attention to informative learning outside class, teachers can spend more class time on guiding pair and group work, as well as task-based and interactive higher-level learning activities (Jong, 2017). As such, lesson time in face-to-face online classrooms should replenish teaching materials given outside of class. Teachers can have more room to assist students in engaging and real-world applications on the basis of self-guided tutorials and quizzes (Stöhr et al., 2020). This helps increase the class time for collaborative activities in music learning.

Invited by a local secondary school in Hong Kong, our research team helped organize a music learning program for $122 \mathrm{~S} .2$ students to learn music. This study designed an online folk-talk-singing experience called Shubailan (數白欖) which is a Chinese form consisting of rhythmic storytelling and singing originated as a means for beggars to ask for money in the past. Nowaday, this form of music shows its unique features of cultures, singing, performance and lyrics, particularly about the rhythm, beat and sentence styles of lyrics. To motivate students in music learning and best use the face-to-face class time during the lessons, the researchers designed the flipped classroom approach with the use of a mobile application called muyu (木魚) to engage students in making Shubailan compositions during the music lessons. Such an innovative approach in music instructions motivates students to study the preassigned materials before the face-to-face online sessions, thus making students more active in performing their work during the lessons.

As a qualitative research, we strive not to generalize this Shubailan learning in music online lessons as common to all secondary school students. Rather, we are interested in documenting the pedagogical considerations within the context of 
music learning in an online flipped classroom approach amid the outbreak. For this purpose, the following questions were addressed:

1. How do students perceive the lesson preparations and face-to-face online sessions throughout the Shubailan online learning experience?

2. What are the perceived benefits of the online flipped classroom approach in music learning with the use of musical instrument apps?

\section{Methodology}

\subsection{Research design}

We conducted a mixed method case study with a learning satisfaction survey, teachers' observations and semi-structured interviews to investigate the aforementioned research questions. The data is used to describe a case in-depth in real-life comprehensively. We recruited 122 Secondary 2 students in four classes in a Hong Kong secondary school to participate in a 6-lesson Shubailan online experience in a flipped classroom approach during the COVID-19 pandemic. All students had not learnt Shubailan in their music studies before.

We designed an online flipped classroom environment where students needed to watch six recorded videos in a learning management platform Google Classroom at their leisure time before their music lessons. During the six online face-to-face lessons, a music teacher (the second author) taught 122 students from four classes to create their Shubailan work based on music knowledge including Cantonese opera, lyrics writing, music accompaniment and instrument from the recorded videos. Students were classified into five of a group and the students will create and perform a Shubailan song in a group. In each lesson, the music teacher encouraged the students to work cooperatively whilst engaging in the muyu playing tasks. In addition, the teacher held whole-class discussion and group performance at the end of each lesson to demonstrate their work. Throughout the six online face-to-face lessons, teachers can review how students can have further improvement and they can appreciate each group's work. The teacher and two teaching assistants circulated the online music room to interact with students, watching their Shubailan performances or presentations, and helping them tackle the challenges they encountered.

In the study, we are interested in understanding whether students acquire their Shubailan making effectively in an online flipped classroom setting with the use of a mobile instrument application muyu. After the six lessons, an evaluation was conducted using qualitative and quantitative empirical research methods. To collect qualitative data, we applied techniques of participant observation using both passive and active participation methods including photo taking, field notes and document analysis (e.g., teaching materials, students' work). Furthermore, we applied the technique of semi-structured interviews using a set of predefined questions as guideline (Kallio et al., 2016). In addition, we applied a learning satisfaction questionnaire in a 5-likert scale to receive feedback regarding how students perceived the learning experience of Shubailan online learning (Table 2). The questionnaire 
comprised eight questions to measure students' view (e.g., "I have a more flexible learning mode that I can learn at my own pace as the videos are available at all times online."). These items were adapted from course satisfaction and motivational surveys based on the benefits of online learning (e.g., Ng \& Chu, 2021b; Li et al., 2020). The factors were hypothesized to facilitate students' learning and attitudes towards music online learning (e.g., flexibility, perceived ability, interest). First, flexibility was assessed by questions 1,2 and 8 to measure whether our online learning design could effectively facilitate students' flexible learning mode. Second, interest was assessed by questions 3, 4 and 6 (e.g., It is more interesting than the traditional face-to-face classroom music learning). Third, question 5 measured students' perceived ability about Shubailan concepts. Fourth, question 7 measured students' engagement and interactivity. Other than conducting the survey, we administered a knowledge test before and after the online music learning experience to evaluate the Shubailan creation ability.

\subsection{Instructional design}

After watching the preassigned recorded videos in Google Classroom for lesson preparation, the face-to-face online learning activities will focus on composing, performance and appreciation to cultivate students' creativity and music appreciation ability. Here is an example for an online music lesson. At first, students will listen to a popular rap by FAMA (a HK pop rap artist) and teachers asked them to state the differences between pop rap and Shubailan. Then, teachers guided students to mark the zhengban and diban ( $X$ and $X$ ) in selected part from the video, and tried to perform it out. Other classmates then gave comments on whether the performers acted correctly. After that, the teacher separates the class into five of a group. They composed and performed their song under the assigned topic ' $M y$ favourite food' (see student's work, Fig. 1). Students will have ten minutes to improve their work with what they learnt in each chapter, and each group of students would have two minutes to perform and present their work (e.g., elements

Fig. 1 A mobile instrument app called muyu to perform Shubailan pieces

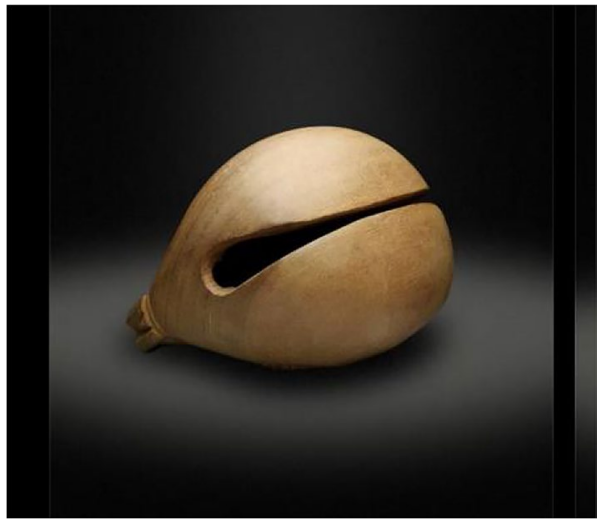


of Cantonese opera, main features) in the shared screen of Zoom, a web conferencing software. The requirements of students' work are as follows:

- Each work should have at least four sentences.

- Each sentence should have three, five or seven words only.

- Present their work with buyu ( $卜$ 魚) to show the zhengban and diban ( X and X).

Regarding the musical instrument application, we used a user-friendly mobile service called muyu which could allow students to create and perform their Shubailan pieces (Fig. 2). Students could choose the hitting sound in the setting first. When they use a figure to touch the muyu on the screen, a sound will be given out. After the student performance, teachers guided students to appreciate each other's work by asking questions like "Do you think this Shubailan script transforms smoothly?", "Any students can think of another word that also rhymes here?" These questions could encourage students to co-build constructive ideas to polish each other's Shubailan pieces. The details for lesson preparation and lesson activities are described in Table 1.

\section{Results}

In what follows, we present the quantitative and qualitative results of Shubailan online learning experience during the lesson preparation and face-to-face online sessions in an online flipped classroom. After attending six lessons of Shubailan music learning, all students were invited to complete a 5-point Likert scale $(n=122)$ and 30 of them were further invited to review the recorded videos and reflection of their Shubailan online learning experience.
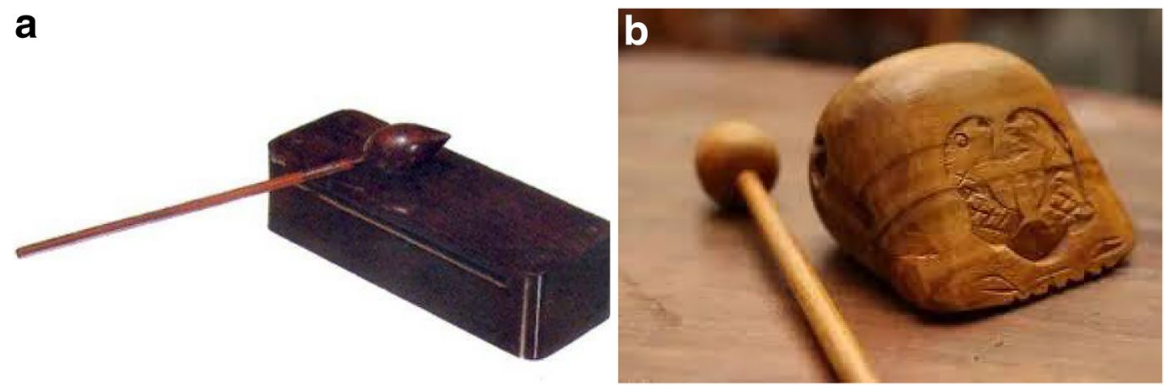

Fig. 2 (a) Buyu (b) Muyu 
Table 1 Details of lesson preparation and lesson activities

Lesson preparations

Music theory in Shubailan (Appendix 1)

- The four basic feats of a Cantonese opera performer (chang唱、zuo做、nian吟、da打).

- The main features, structure and characteristics of shubailan.

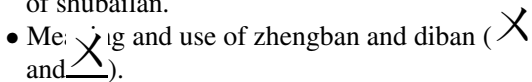

- Use of chenzi (襯字)

Video (8.5 min): https://www.youtube.com/ watch?v=li_izCpNNI0\&feature $=$ youtu.be

Music instrumental in Shubailan (Fig. 2)

- Introduction to Chinese Percussion Instruments: buyu (卜魚) and muyu (木魚)

Video (12.5 min):

https://www.youtube.com/watch?v=sXPqX eg9kYo

Classic and modern examples of Shubailan

(Fig. 3): Students are required to watch at least eight minutes of the videos for further discussion in their classes

- Two classical examples of Shubailan

○Hubugui (胡不歸之尉妻) https://www.youtube. com/watch?v=t3Q8J7KB0mc

$\circ$ Huatian Baixi (花田八喜) https://www.youtu be.com/watch? $\mathrm{v}=\mathrm{MBEVjUmVrm} 8$

- Two modern examples of Shubailan or rap singing

- A marketing advertisement from HK Public

Housing Association (1.2 min)

https://www.youtube.com/watch?v=7yhrOdDU_ ZA

- A popular rap by FAMA, a popular signer in

Hong Kong (3.5 min)

https://www.youtube.com/watch?v=deFT4

Xo6ucM
Lesson activities in groups

- Perform the four basic skills in Cantonese opera.

- Study and perform the music score in Shubailan according to their features, structures, zheng ban and diban.

- Sing a Cantonese opera with the use of zhengban and diban.

- Discuss which words in the Shubailan piece

- Mark the zhengban ( X) and diban ( work.

- Experience the musical instrument application muyu.

- Produce different sounds in the mobile application muyu.

- Make a Shubailan work based on the music theories with the musical instrument application (Fig.4).

- Use a mobile instrument application muyu to perform students' work in front of classmates.

- Appreciate the classical Shubailan pieces and discuss the music skills and knowledge involved.

- Understand the everyday use of Shubailan.

- Improve students' work through small-group discussion with the three examples.

\subsection{Perceptions on lesson preparations}

\subsubsection{Qualitative results}

During the lesson preparation, students needed to complete five instructional videos about basic knowledge of Shubailan music learning. Prior studies have claimed that the ideal length for the video lesson is eight to twelve minutes (Abeysekera \& Dawson, 2015; Ronchetti, 2010). Thus, in our study, we designed and recorded each video will be around seven minutes on average for students to complete lesson 

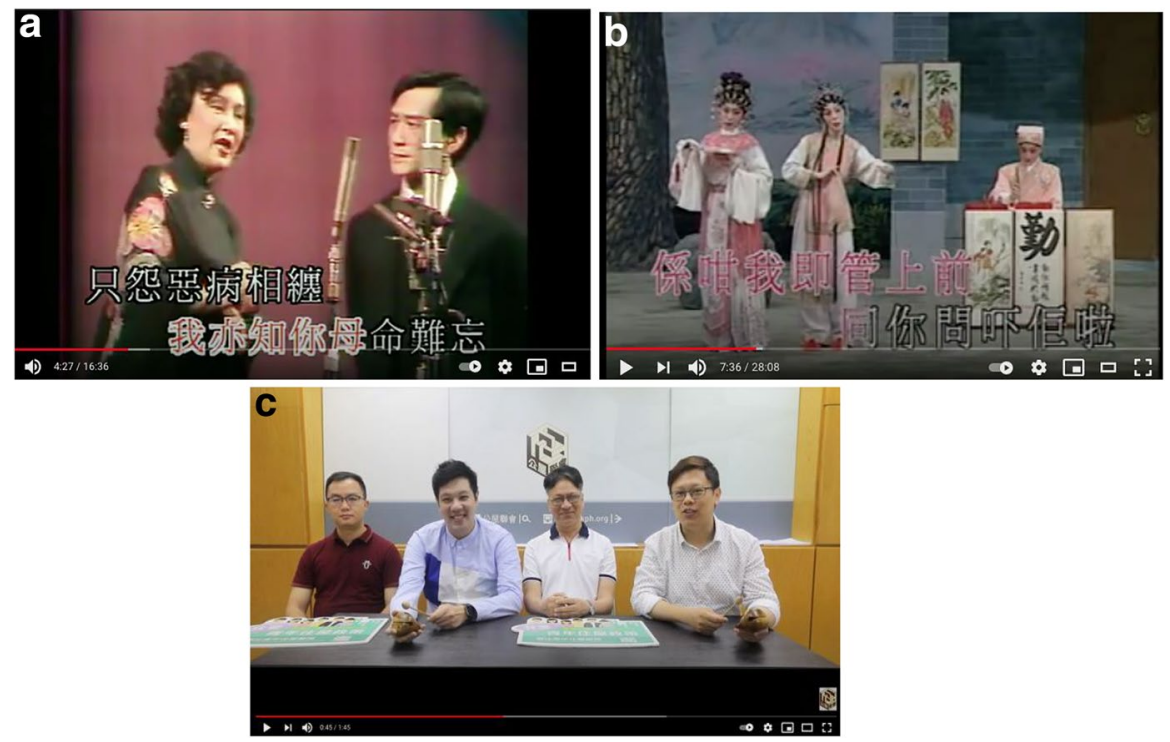

Fig. 3 a Hubugui b Huatian Baixi c An advertisement from HK Public Housing Association

preparation before their face-to-face online classes during the leisure time. Students' feedback for watching the recorded video were divided into four aspects: to learn an interesting topic in music $(n=16)$; to entertain myself during the leisure time $(n=10)$; to help complete an assignment for teachers $(n=8)$; and to achieve a better grade $(n=3)$. Unlike the study of Zainuddin, Shujahat, et al. (2019), Zainuddin, Zhang, et al. (2019)), which suggested that most students do not like pre-recorded video lectures or studying content outside of class time due to a lack of motivation, our study showed that students have interest in reviewing the videos in an online flipped classroom setting.

Many students suggested that the recorded videos uploaded to Google Classroom could support their self-directed learning. As one interviewee claimed: "I can watch

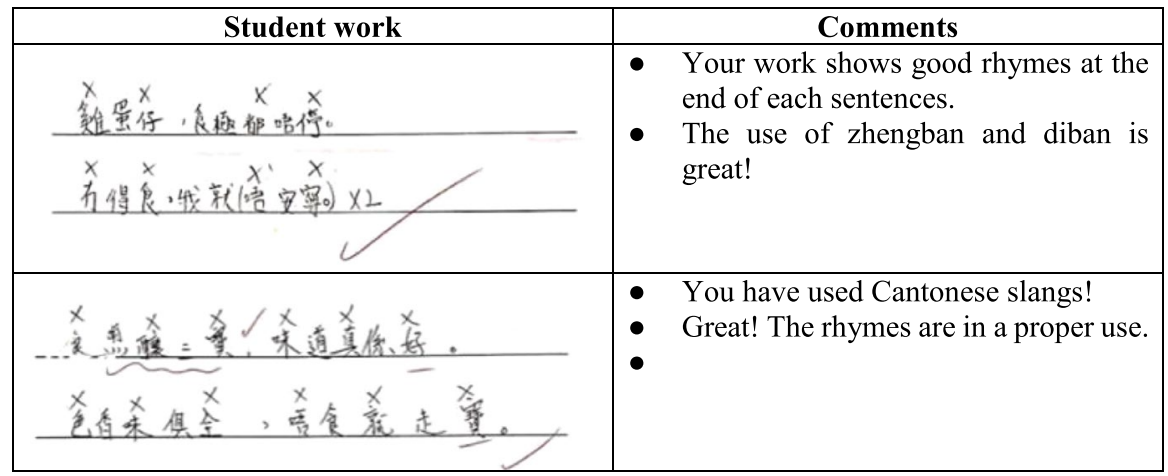

Fig. 4 Student Shubailan work 
the recorded video whenever I want and wherever I am. I can use the functions like fast forward and pause to any point I want to review. It is useful for me since I am not a music guy. This can help me review [the concepts] that I need to create my Shubailan pieces." A teaching assistant reported that the students enjoyed watching the recorded videos instead of asking her about the teaching content in the smallgroup discussion forum. This online flipped classroom approach tended to encourage students with strong self-initiative (Li et al., 2020). However, in this study, students seem to actively prepare their lessons with the preassigned instructional videos. One possible reason is that students may feel bored and they would like to attend some leisure activities such as exploring interesting topics like Shubailan during the class suspension. Like the study of $\mathrm{Ng}$ (2021), which suggested that students enjoyed having some online extracurricular activities of artificial intelligence learning during their class suspension to cope with boredom during home-schooling.

\subsubsection{Quantitative results}

According to the learning satisfaction survey concerning lesson preparation, students gave the most positive response for having a better understanding of the Shubailan concepts through watching preassigned instructional videos during lesson preparation $(M=3.30, S D=0.85)$, indicating that they were satisfied with the information quality such as demonstrations and knowledge delivery in the recorded videos. This is consistent with other studies, poor media quality has a negative effect on students' use of online learning tools and platforms (Li et al., 2020). One student with middle music creation level said that, "In the traditional classroom, I listened to teacher's instruction most of the time, sang songs and played/ performed recorders together. We had little time to create music and get feedback from teacher or classmates. However, the online flipped classroom approach helped me a lot in music learning." Another study gave a positive comment: "I can learn interesting content at my leisure time. Before the class, I watch the videos and the notes helped me to think refine my Shubailan work. Creations can't just happen immediately during lessons. I need time to rethink and recreate to make a better work."

Second, the online flipped classroom approach allows students to watch the instrumental videos several times to improve their learning based on their needs and preferences during lesson preparation $(M=3.21, S D=0.67)$. Other studies also claimed that students would easily forget the content taught; however, using instructional videos allowed students to review the teaching content again ( $\mathrm{Li}$ et al., 2020; Ng, Reynolds, et al., 2020; Ng, Shi, et al., 2020). This could help students to take time on reviewing the preassigned learning materials without lagging behind $(M=3.19 ; S D=0.84)$. "I can't pay attention during online lessons and music is not my cup of tea. I would listen to the audio/video materials many times at home, specifically for the content that I do not understand well." This way, the combination of recorded videos and face-to-face online communication had a more positive effect on flexible learning than simply adopting either mode (Giesbers et al., 2014). Finally, this approach supported students' flexible learning and self-regulated learning to facilitate students to create music during class suspension. Table 2 indicates 
Table 2 Learning satisfaction of Shubailan online learning in an online flipped classroom approach

\begin{tabular}{ll}
\hline Statements & Mean $(\mathrm{n}=122)$ \\
\hline $\begin{array}{l}\text { 1. I have a more flexible learning mode that I can learn at my own pace as the videos } \\
\text { are available at all times online. }\end{array}$ & 3.16 \\
2. It allows me to take time on reviewing the material without lagging behind. & 3.19 \\
3. I get less frustrated towards the musical instrument application and music making & 3.16 \\
during the online face-to-face lessons. & 3.18 \\
4. I am interested and capable of exploring Shubailan in a deeper manner during the & \\
lessons. & 3.30 \\
5. The demonstrations and knowledge delivery in the recorded videos give me a better \\
understanding of the Shubailan concepts. \\
$\begin{array}{l}\text { 6. It is more interesting than the traditional face-to-face classroom music learning. } \\
\text { 7. It creates a dynamic, engaging and interactive classroom which focuses on student }\end{array}$ \\
$\begin{array}{l}\text { interactions and music creation. } \\
\text { 8. It allows me to watch the instrumental videos several times. }\end{array}$ \\
\hline
\end{tabular}

that the learning satisfaction of the online flipped classroom learning approach regarding music creation.

\subsection{Perceptions on face-to-face online sessions}

\subsubsection{Student interaction in a web-conferencing software}

Regarding the student interaction during the face-to-face online sessions, Table 3 demonstrated that most students gain a significant improvement in Shubailan knowledge $(M=68.85, S D=18.38, p<0.01)$. The music teacher commented on students' work: 'I appreciate students' work. At the beginning, none of my students know Shubailan. Now, students know many learning elements on the focus of Shubailan such as Cantonese opera, lyrics writing, music accompaniment and instrument playing. In addition, from my observation, students can easily play the beats of their Shubailan work using the music app in an online flipped classroom." A student gave a positive reply: "In the past, I don't like Chinese Opera or muyu - it's an old stuff to me. However, the music app and e-learning method refresh my perceptions to this traditional Chinese music culture. It's not that old-styled!".

In terms of students' satisfaction, students agreed that the online flipped classroom gave them great opportunities to collaborate with other class students during their face-to-face online sessions $(M=3.35, S D=0.94)$. They believed that

Table 3 Students' learning ability in pre-posttest with a total score $100(n=122)$

\begin{tabular}{llll}
\hline Learning ability & Pre-test & Post-test & Paired t test \\
\hline Mean & 25.74 & 68.85 & $11.85^{*}$ \\
SD & 25.14 & 18.38 & \\
\hline$* \mathrm{p}<0.01$ & & &
\end{tabular}


the face-to-face online music performance and appreciation in Zoom with the use of digital muyu could create a dynamic, engaging and interactive environment to enhance student collaboration in the Shubailan creation processes. Eleven students indicated directly in their interviews that this was one of their reasons they enjoyed their music creation during the face-to-face online sessions in a flipped classroom. A student commented, "Although we [students] cannot meet each other at school or go to classmates' home to complete the [Shubailan] project, we could still make use of Zoom to do our project. Other than verbal communication, there are some interesting features of Zoom such as whiteboard, giving likes and discussion forums for us to express during the class." Similarly, Jessica, another student said, "Teachers used interactive whiteboards to teach beats and clap. We can talk and sing with rhythm and play with varied rhythm patterns with the mobile app [muyu] by screen sharing." Another student reflected, "Other than voicing our opinion during the lessons, we can discuss in the break-out room and give 'likes' and 'thumbs' [to my classmates]. These interactive features of web-conferencing softwares such as breakout rooms, annotation tools and whiteboards provided digital affordances for students to sustain their music learning online.

Our students' comment and survey responses aligned with some recent studies that these web annotation tools can enhance students' knowledge sharing, collaboration, and visual presentations of concepts. For example, Tseng and Yeh (2018) demonstrated that secondary school students were significantly correlated with reading ability by highlighting the structure of paragraphs in an English reading comprehension. Ng, Reynolds, et al. (2020), Ng, Shi, et al. (2020)) explored how visual presentations of geometry in a computer application can produce a positive learning outcome to simulate methodical thinking especially with the support of $3 \mathrm{D}$ printing technologies. In music learning, teachers can incorporate interactive whiteboards with digital pens through singing with lyrics and pictures (e.g., identifying the underline and circled rhyming words, picking the pictures for the song from clip art), teaching notation and composition, and interpreting music through drawing phrases (Ng \& Ho, 2021; Nolan, 2009).

\subsubsection{Student interaction with a musical instrument application}

Students may not have musical instruments at home during the pandemic. Using a musical instrument application during the online face-to-face lessons would be an alternative mode for students to perform in front of others and appreciate others' work through the web-conferencing software. A student commented, "Though I don't have any music instruments at home, I can still enjoy playing music through the music app [тиуu]. My teacher told me [in the lesson] that there are other music mobile apps available such as Garageband. Although these applications may not give me a perfect learning experience compared with the real ones, this is understandable. I still enjoy it!" Similarly, another student reviewed, "Although I miss the old days of playing instruments and singing songs with classmates in the classroom, performing in front of the camera in such an online music conference with a mobile app can be interesting too." Moreover, a student who did not have a strong background in music reflected that, "I don't know music. But if I have some preassigned 
music patterns or beats in the settings of the music app, I can easily create some songs [during the lessons]."

Combining the music applications in the flipped classroom approach offered music making opportunities for K-12 students to embrace different music technologies such as auto-accompaniment software, digital audio workstation, audio recordings, electronic instruments, music notation software and interactive whiteboards (e.g., Bauer et al., 2012). In fact, these emerging technologies successfully present extra learning opportunities for music learning. Prior studies provided evidence for these musical instrument apps that could effectively enhance students' collaborative informal music learning, learning engagement and attitude in the online classrooms to acquire skills and concepts in music learning. For example, Väkevä (2010) found that informal pedagogy with the use of Garagenand could encompass various modes of digital creation in face-to-face pedagogical situations, informal learning, and open networked learning environments and musical online communities. The practice of playing instruments with features through recording and rehearsing could allow students to perform live in an online learning environment or even an online or music appreciation group. Moreover, Sabet (2020) examined the experiences of secondary school students using GarageBand for iPad in a music class to compose original music. It was found that students could actively share and present their music pieces during the lessons. Based on qualitative analysis, performing, recordings and rehearsing with the use of music technologies would encourage students to think creatively and even tackle instructional roadblocks of music learning. In addition, Jaffurs (2004) reflected that the proliferation of computers, tablets, and smartphones has resulted in music applications such as GarageBand in being some of the most widely distributed musical instruments to conduct informal music learning practices. As such, musical instrument apps have a constructive role in the online music learning community to effectively stimulate students' creativity across other music education contexts.

\section{Discussion}

\subsection{Overview of the main results}

Music educators identified several challenges including lack of teaching resources, low priority given to music in schools, time to teach music and adequate preparation time (Russel-Bowie, 2009). These issues became more challenging during the pandemic (e.g., Baratè et al., 2020; Daubney \& Fautley, 2020). For example, students lack musical instruments at home and could not play and perform instruments together as usual. Even worse, compared with other subjects such as language and science, schools tended to give a lower priority to music learning and teachers did not have enough online learning resources and preparation time to transform their teaching online.

According to the data analysis, the results showed that the online flipped classroom approach helped solve part of the practical problems that teachers met in online music learning contexts and led to more interactive time for higher-order thinking 
activities such as online music appreciation, performance and making during the online face-to-face lessons. By analyzing the responses of students and instructors, this section discusses three aspects of online flipped classroom approach. First, selfregulated instructional videos in a learning management platform encouraged students to have a flexible learning preparation to gain some factual knowledge about Shubailan before their lessons. Second, in-class interactive activities engaged students in making Shubailan pieces via collaboration, discussion and creation. Third, using musical instrument apps allowed students to perform and appreciate music especially for those without physical musical instruments at home.

\subsection{Flexible lesson preparation}

The online flipped classroom approach engaged students in studying preassigned materials such as instructional videos before the online face-to-face lessons in a flexible mode, which could greatly reduce instructors' direct teaching time. Online flipped classroom offered a variety of learning modes such as individualized and group work, creating a seamless and flexible environment satisfying students' autonomous motivation needs (Wang, 2017). For example, Wei et al (2020) showed that 88 middle school students could significantly improve their mathematical learning performance by watching prerecorded video lectures and completing their learning activities before class in a flexible online flipped classroom. In another study, Jing (2018) reflected that online flipped classroom approach could internalize students' music learning and enhance their learning interest, application of music and cultural knowledge. Students could also enjoy audio and visual materials to learn music at their leisure time in enrichment activities before and after classroom to broaden their horizons (Jing, 2018).

In our instructional design, lesson preparation provided flexibility which allowed students especially those without a strong background in music knowledge to understand and follow the concepts at their own paces by watching the recorded videos again. Some students with no music understanding problems nevertheless watched the recorded videos to better prepare part of the course content before lessons. This enabled them to thoroughly understand the content of the course and prepare well for making their Shubailan pieces during the face-to-face online lessons. In addition, as the online flipped classroom approach was integrated into Google Classroom, the secondary school's learning management system, all students access the teaching materials without much technical problems. Overall, an effective lesson preparation could reduce direct teaching hours and encourage more interactive and collaborative activities during the face-to-face online classes to stimulate students' higherorder thinking and creativity, which could help solve practical problems for music educators.

\subsection{Collaborative online face-to-face learning environment}

The potential benefits of online flipped classrooms in music education could reduce didactic teacher-led activities greatly such as music theories, music history, aural 
training and the acquisition of notational skills (Ruokonen \& Ruismäki, 2016; Southcott \& Crawford, 2011). In our study, the online flipped classroom approach with the use of musical instrument apps helped offer students learning opportunities to create their own Shubailan pieces in groups even without physical musical instruments at home.

Using technology in music education could provide students creative and collaborative possibilities via meaningful music making activities (Crawford, 2017; Leong, 2012). In our study, the features in the web-conferencing software such as breakout rooms, annotation tools and giving 'claps' or 'likes' would provide a virtual platform for students to perform in front of others and appreciate each other's work with a music mobile application. This meaningful and contemporary online music activity brought the outside world into the music classrooms such as how Shubailan was used in the cultural and marketing fields, or everyday topics for creation, which provided authentic learning opportunities for students to learn music. Although we only focused on a musical instrument application in this study, there was great potential for understanding other music technologies into music education.

By developing the flipped classroom approach, this case study explored how teachers engage students in Shubialan music making with mobile instrument application and solved some practical problems related to music teaching amid the COVID-19 pandemic at a secondary school in Hong Kong. The success of this mode has several implications for the practice of blended learning and online learning. First, students are motivated to take full advantage of flexible lesson preparation and interactive activities during the online face-to-face classes. Second, the use of technologies in music education (e.g., recorded videos, web-conferencing software, musical instrument application) is a strong contributor to learners' engagement and satisfaction in online learning. Third, the effects will be further enhanced if meaningful music mobile services, learning tools and platforms are integrated systematically. More real-time collaborative tools should be used to promote interactions between students and teachers, even in face-to-face classes. The Shubailan music project enabled students to use technology to learn music compositions, culture and histories, and instruments to encourage students' music making, sharing and collaborating processes. It was believed that, under the new norm of learning and teaching, not only music, but all educators from other subject disciplines will need to be prepared for a shifting paradigm for online or blended teaching.

\section{Conclusion}

While a growing body of studies on flipping the classroom has generally examined its effectiveness such as motivation, ability and high order thinking skills among different subject disciplines (e.g., Jong, 2019; Zainuddin, Shujahat et al., 2019; Zainuddin, Zhang et al., 2019), few have undertaken how the online flipped classroom approach to examine the learning processes involved in music learning. During the pandemic, we explored how this approach may serve to support creative music making with the use of a mobile instrument and a web-conferencing software in a secondary school in Hong Kong. One of the contributions is that 
this study offers evidence to support the online flipped classroom approach with musical instrument apps as computer-based support for music learning. This may serve future investigations into how music learning experiences with other mobile services and online pedagogies can be scaffolded.

Some limitations of this study are acknowledged. The first limitation derives from the exploratory nature of this case study in an authentic online learning setting since there is no control group defined to compare the learning outcomes of the experimental group. Moreover, we did not design the questionnaire thoroughly by filling more questions in each construct; as such, we adopt qualitative approach to understand and triangulate how students perceived such online flipped classroom approach with the use of a music application. Second, the instructors received only a type of web-conferencing tool and musical instrument application to conduct the Shubailan teaching. The results may vary to some degree based on instructors' characteristics, technological tools, and learning activity design. Further research on improving the effects of the flipped classroom approach is necessary. Other useful teaching strategies, tools and activities for instructional design should be explored in future work.

\section{Theoretical Implications}

As a theoretical contribution, the online flipped classroom approach with the use of music technology was constructed based on the practice and reflection from a case study in an authentic music classroom setting. Overall, this study provides an empirical and theoretical basis for music education to promote the use of digital technology. A list of recommendations for music teachers are as follows:

Use computer-aided instruction such as recorded videos, social media tools and music mobile services in developing creativity and imagination, improving music skills, cultivating critical responses in music learning.

Design a set of online curriculum resources among educators to smoothly transform music learning in an alternative online mode.

Adopt the online flipped classroom approach to minimize the direct teaching and maximize online collaborative opportunities such as performance, appreciation and music creation to stimulate students' higher order thinking.

Use musical instrument apps to encourage students to co-construct, rearrange and create music pieces in an online community, although these virtual music instruments may not thoroughly simulate the mechanics of a physical music instrument.

Other music mobile services such as social media, digital libraries and editing software are also useful to transform traditional classrooms into music creation learning. 


\section{Appendix 1 Music theory in Shubailan (Chow, 2016)}

\section{Four performance skills in Cantonese opera}

The performance skills of Cantonese opera actors are divided into four basic categories, Chang, Zuo, Nian and Da.

\section{Chang「唱」}

There are two ways of singing to match different characters, including Pinghou and Zihou. Pinghou is the tone of ordinary speech, mostly male characters sing in Pinghou. Zihou is an octave higher than the Pinghou, mostly female characters sing in this voice with false accents.

\section{Zuo「做」}

Zuo means the physical performances of characters, including gestures, stepping, walking position, closing eyes, doing hands, body shape, sleeves, Lingzi Gong, Xu Gong, water hair, abstract performance and traditional exercise frame.

3. Nian「吟」

Nianbai means speaking out the dialogue. Use words to explain the scenes and the thoughts and feelings of the characters.

4. Da「打」

Da means martial arts, such as dancing water sleeves, playing with fans, martial arts swords and spears, playing sticks and swings, and waving flags.

\section{Music score of Cantonese Opera}

Cantonese opera records the melodies and tone with GongChe, a type of Chinese music score.

\begin{tabular}{llll}
\hline Symbols & Types & Descriptions & \\
\hline$X$ & Zhengban & Upbeat & A strong beat appears where there are lyrics \\
X & Diban & & A strong beat appears where there are no lyrics \\
Z & Zhengding & Downbeat & A weak beat appears where there are lyrics \\
& Diding & & A weak beat appears where there are no lyrics \\
\hline
\end{tabular}




\section{References}

Abeysekera, L., \& Dawson, P. (2015). Motivation and cognitive load in the flipped classroom: definition, rationale and a call for research. Higher Education Research \& Development, 34(1), 1-14.

Adileh, M. T. (2012). Teaching Music as a University Elective Course through e-Learning. Australian Journal of Music Education, 1, 71-79.

Aucouturier, J. J., \& Canonne, C. (2017). Musical friends and foes: The social cognition of affiliation and control in improvised interactions. Cognition, 161, 94-10.

Baratè, A., Haus, G., \&Ludovico, L. A. (2020). Learning, teaching, and making musictogether in the COVID-19 Era Through IEEE 1599. In 2020 International Conference on Software, Telecommunications andComputer Networks (SoftCOM) (pp. 1-5). IEEE.

Bauer, W. I., Hofer, M., \& Harris, J. (2012). Grounded Tech Integration Using K-12 Music Learning Activity Types. Learning \& Leading with Technology.

Bauer, W. (2014). Music learning and technology. New directions: a journal of scholarship, creativity and leadership in music education, 1(1).

Sangiorgio, A. (2015). Collaborative creativity in music education: children's interactions in group creative music making (Doctoral dissertation, University of Exeter).

Biasutti, M., \& Concina, E. (2013). Music education and transfer of learning. Journal of Communications Research, 5(3).

Biasutti, M. (2015). Creativity in virtual spaces: Communication modes employed during collaborative online music composition. Thinking Skills and Creativity, 17, 117-129.

Bowman, J. (2014). Online learning in music: Foundations, frameworks, and practices. Oxford University Press.

Cho, S., Baek, Y., \& Choe, E. J. (2019). A strategic approach to music listening with a mobile app for high school students. International Journal of Music Education, 37(1), 132-141.

Chow, S. S. (2016). Tradition and innovation: adaptation in Cantonese opera. Retrieved from http:// repository.hkbu.edu.hk/cgi/viewcontent.cgi?article=1288\&context=etd_oa. (Doctoral dissertation, Hong Kong Baptist University).

Chu, S. K. W., Wu, J., Kwan, C. W. S., \& Lai, J. H. Y. (2019). Wiki-based collaborative writing: A comparative study on first and second language writing among chinese secondary students. International Journal of Modern Education and Computer Sciences, 11(1), 1-10.

Crawford, R. (2017). Rethinking teaching and learning pedagogy for education in the twenty-first century: blended learning in music education. Music Education Research, 19(2), 195-213.

Daubney, A., \& Fautley,M. (2020). Editorial Research: Music education in a time of pandemic. British Journal of Music Education, 37(2), 107-114.

de Bruin, L. R. (2021). Instrumental music educators in a COVID landscape: A reassertion of relationality and connection in teaching practice. Frontiers in Psychology, 11, 3995.

Dong, A. M., Jong, M. S. Y., \& Shang, J. J. (2019). Achievement pathway of higher-order thinking through classroom interactions in the flipped classroom. Modern Educational Technology, 29(2), 46-51.

Edward, C. N., Asirvatham, D., \& Johar, M. G. M. (2018). Effect of blended learning and learners' characteristics on students' competence: An empirical evidence in learning oriental music. Education and Information Technologies, 23(6), 2587-2606.

Giesbers, B., Rienties, B.,Tempelaar, D., \& Gijselaers, W. (2014). A dynamic analysis of the interplaybetween asynchronous and synchronous communication in online learning: The impactof motivation. Journal of ComputerAssisted Learning, 30(1), 30-50.

Ho, W. C. (2007). Students' experiences with and preferences for using information technology in music learning in Shanghai's secondary schools. British Journal of Educational Technology, 38(4), 699-714.

Jaffurs, S. E. (2004). The impact of informal music learning practices in the classroom, or how I learned how to teach from a garage band. International Journal of Music Education, 22(3), $189-200$.

Jing, C. (2018). TheImplementation and Research of Flipped Classroom Teaching of Public MusicCourses in Colleges and Universities under the Background of SPOC_— Taking theMulticultural Perspective of Western Music as an Example. In 20183rd International Social Sciences and Education Conference (pp. 464-467).ISSEC. 
Johnson, C. (2017). Teaching music online: Changing pedagogical approach when moving to the online environment. London Review of Education, 15(3), 439-456.

Johnson, C., \& Merrick,B. (2020). Enabling music students' well-being through regular Zoom cohortchats during the COVID-19 crises. Teaching,technology, and teacher education during the COVID-19 pandemic: Stories from thefield, 261-264.

Jong, M. S. Y. (2017). Empowering students in the process of social inquiry learning through flipping the classroom. Journal of Educational Technology \& Society, 20(1), 306-322.

Jong, M. S. Y., Chen, G. W., Tam, V., \& Chai, C. S. (2019). Adoption of flipped learning in social humanities education: The FIBER experience in secondary schools. Interactive Learning Environments, 27(8), 1222-1238.

$\mathrm{Hu}$, X. (2019). Evaluating mobile music services in China: An exploration in user experience. Journal of Information Science., 45(1), 16-28.

Kallio, H., Pietilä, A. M., Johnson, M., \& Kangasniemi, M. (2016). Systematic methodological review: developing a framework for a qualitative semi-structured interview guide. Journal of Advanced Nursing, 72(12), 2954-2965.

King, A., \& Himonides, E. (Eds.). (2016). Music, technology, and education: Critical perspectives. Routledge.

Kruse, N. B., \& Veblen, K. K. (2012). Music teaching and learning online: Considering YouTube instructional videos. Journal of Music, Technology \& Education, 5(1), 77-87.

Lee, S. W., \& Freeman, J. (2013). Echobo: A mobile music instrument designed for audience to play. Ann Arbor, 1001, 48109-52121.

Leong, S. (2012).Navigating the emerging futures in music education. Journal of Music, Technology \& Education, 4(2-3), 233-243.

Li, X., Yang, Y., Chu S.K.W., Zainuddin Z. \& Zhang Y. (2020)Applying blended synchronous teaching and learning for flexible learning inhigher education: an action research study at a university in Hong Kong, Asia. Pacific Journal of Education. https://doi.org/10.1080/02188791.2020.1766417

$\mathrm{Ng}$, T. K. (2021). New interpretation of extracurricular activities via social networking sites: A case study of artificial intelligence learning at a secondary school in Hong Kong. Journal of Education and Training Studies, 9(1), 49-60.

Ng, D. T. K., \& Chu, S. K. W. (2021a). Motivating Students to Learn AI through Social Networking Sites: A Case Study in Hong Kong. Online Learning, 25(1), 195-208.

Ng, D. T. K., \& Chu, S. K. W. (2021b). Motivating Students to Learn STEM via Engaging Flight Simulation Activities. Journal of Science Education and Technology, 1-22.

Ng, T. K., Reynolds, R., Chan, H. M. Y., Li, X. H., \& Chu, S. K. W. (2020). Business (teaching) as usual amid the COVID-19 pandemic: A case study of online teaching practice in Hong Kong. Journal of Information Technology Education: Research, 19, 775-802.

Ng, T. K., \& Ho. S.Y. (accepted, 2021). Teaching Creatively: Case Studies with small group Zoom synchronous learning in a summer program. Journal of Communication and Education.

Ng, O. L., Shi, L., \& Ting, F. (2020). Exploring differences in primary students' geometry learning outcomes in two technology-enhanced environments: dynamic geometry and 3D printing. International Journal of STEM Education, 7(1), 1-13.

Nielsen, S. G., Johansen, G. G., \& Jørgensen, H. (2018). Peer learning in instrumental practicing. Frontiers in Psychology, 9, 339.

Nolan, K. K. (2009).SMARTer music teaching: Interactive whiteboard use in music classrooms. General Music Today, 22(2), 3-11.

Philippe, R. A., Schiavio, A., \& Biasutti, M. (2020). Adaptation and destabilization of interpersonal relationships in sport and music during the Covid-19 lockdown. Heliyon, 6(10), e05212.

Pike, P. D. (2017). Improving music teaching and learning through online service: A case study of a synchronous online teaching internship. International Journal of Music Education, 35(1), 107-117.

Pike, P. D., \& Shoemaker, K. (2013). The effect of distance learning on acquisition of piano sight-reading skills. Journal of Music, Technology \& Education, 6(2), 147-162.

Ruokonen, I., \& Ruismäki, H. (2016). E-learning in music: A case study of learning group composing in a blended learning environment. Procedia-Social and Behavioral Sciences, 217, 109-115.

Ronchetti, M. (2010). Using video lectures to make teaching more interactive. International Journal of Emerging Technologies in Learning, 5(2), 45-48.

Russel-Bowie,D. (2009). What me? Teach music to my primary class? Challenges to teaching musicin primary schools in five countries. MusicEducation Research, 11(1), 23-36. 
Sabet, S. (2020). Composing with mobile technology: High school students and GarageBand for iPad. Journal of Popular Music Education, 4(3), 349-369.

Serdaroglu, E. (2020). Exploringthe Use of Youtube by Symphonic Orchestras as An Educational Platform Duringthe Pandemic of Covid-19. EuropeanJournal of Social Science Education and Research, 7(3), 59-66

Southcott, J., \& Crawford, R. (2011). The intersections of curriculum development: Music, ICT and Australian music education. Australasian Journal of Educational Technology, 27(1).

Stöhr, C., Demazière, C., \& Adawi, T. (2020). The polarizing effect of the online flipped classroom. Computers \& Education, 147, 103789.

Tang, T., Abuhmaid, A. M., Olaimat, M., Oudat, D. M., Aldhaeebi, M., \& Bamanger, E. (2020). Efficiency of flipped classroom with online-based teaching under COVID-19. Interactive Learning Environments, 1-12.

Tseng, S. S., \& Yeh, H. C. (2018). Integrating reciprocal teaching in an online environment with an annotation feature to enhance low-achieving students' English reading comprehension. Interactive Learning Environments, 26(6), 789-802.

Väkevä, L. (2010). Garage band or GarageBand®? Remixing musical futures. British Journal of Music Education, 27(1), 59-70.

Wang, F. H. (2017). Anexploration of online behaviour engagement and achievement in flipped classroomsupported by learning management system. Computers \& Education, 114, 79-91

Wei, X., Cheng, I. L., Chen, N. S., Yang, X., Liu, Y., Dong, Y., \& Zhai, X. (2020). Effect of the flipped classroom on the mathematics performance of middle school students. Educational Technology Research and Development, 1-24.

Wise, S. (2016). Secondary school teachers' approaches to teaching composition using digital technology. British Journal of Music Education, 33(3), 283.

Zainuddin, Z., Shujahat, M., Chu, S. K., Haruna, H., \& Farida, R. (2019). The effects of gamified flipped instruction on learner performance and need satisfaction. Information and Learning Sciences, 120(11), 789-302.

Zainuddin, Z., Zhang, Y., Li, X., Chu, S. K. W., Idris, S., \& Keumala, C. M. (2019). Research trends in flipped classroom empirical evidence from 2017 to 2018: A content analysis. Interactive Technology and Smart Education, 16(3), 255-277.

Publisher's Note Springer Nature remains neutral with regard to jurisdictional claims in published maps and institutional affiliations.

\section{Authors and Affiliations}

\section{Davy T. K. NG ${ }^{1}$ (D) Ellen H. L. NG ${ }^{2}$. Samuel K. W. $\mathrm{CHU}^{1}$}

Ellen H. L. NG

nghoilamellen@gmail.com

Samuel K. W. CHU

samchu@hku.hk

1 The University of Hong Kong, Hong Kong, China

2 The Chinese University of Hong Kong, Hong Kong, China 